\title{
NEIBA
}

\section{Dos escombros à liderança: A reconstrução alemã no pós-guerra e suas bases econômicas para as décadas seguintes}

Mario Afonso Massiere y Correa de Moraes Lima

Vínculo Institucional: Mestre em Relações Internacionais (UERJ) e Doutorando em Economia Política Internacional (UFRJ)

\section{Resumo:}

A Alemanha é, e tem sido por décadas, um dos principais atores no sistema internacional. No entanto, ao longo do século XX, a Alemanha foi a grande responsável por duas guerras que marcaram o continente europeu e o mundo, alterando de forma indiscutível o equilíbrio de poder global. Após o final da II Guerra Mundial, a Alemanha se encontrava destruída, ocupada e com pesadas dívidas de reparação de guerra. A ideia que guia esse artigo é entender de que forma ocorreu a reconstrução do Estado alemão no imediato pós-guerra e algumas das consequências do período de ocupação alemão por parte das forças aliadas. Como é possível entender de que forma a mistura entre a reconstrução de uma Alemanha, marcada por um regime nazista e um espírito punitivo por parte dos aliados, foi capaz de resultar em uma das economias mais avançadas do mundo com altíssima rentabilidade em poucas décadas.

Palavras-chaves:

Alemanha; Pós-Guerra; Economia Política Internacional

\begin{abstract}
:
Germany is, and has been for decades, a major player in the international system. However, throughout the twentieth century, Germany was largely responsible for two wars that marked the European continent and the world, undoubtedly altering the balance of global power. After the end of World War II, Germany was destroyed, occupied and with heavy war reparation debts. The idea guiding this article is to understand how the reconstruction of the German state occurred in the immediate post-war
\end{abstract}




\section{NEIBA}

\section{VOLUME VII}

Dossiê: SimpoRI 2018

\section{8}

period and some of the consequences of the German occupation period on the part of the allied forces. How one can understand how the mixture between the rebuilding of a Germany, marked by a Nazi regime and a punitive spirit on the part of the allies, was able to result in one of the most advanced economies of the world with very high profitability in a few decades.

\section{Keywords:}

Germany; Post-War; International Economic Politics 


\section{NEİBA}

\section{Introdução}

A Alemanha é, e tem sido por décadas, um dos principais atores no sistema internacional. No entanto, ao longo do século XX, a Alemanha foi a grande responsável por duas guerras que marcaram o continente europeu e o mundo, alterando de forma indiscutível o equilíbrio de poder global. Após o final da II Guerra Mundial, a Alemanha se encontrava destruída, ocupada e com pesadas dívidas de reparação de guerra. Suas cidades eram pouco mais do que escombros e ainda assim, menos de 30 anos depois, esse mesmo país era uma economia de ponta liderando o continente europeu.

A ideia que guiou esse artigo é entender de que forma ocorreu a reconstrução do Estado alemão no imediato pós-guerra e algumas das consequências do período de ocupação alemão por parte das forças aliadas. Como é possível entender de que forma a mistura entre a reconstrução de uma Alemanha marcada por um regime nazista, junto com a vontade de não permitir que se tornasse uma potência capaz de gerar uma nova guerra mundial e um espirito punitivo por parte dos aliados, foi capaz de resultar em uma das economias mais avançadas do mundo com altíssima rentabilidade em poucas décadas. Quais os fatores políticos e econômicos que permitiram esse grande salto nas décadas de 1940 e 1950? Seria somente por conta da destruição trazida pela guerra? Se sim, por que isso não ocorreu em 1920, se não, quais outros motivos estiveram por trás da reconstrução e do desenvolvimento alemão.

Para melhor compreender o que foi a reconstrução alemã, esse artigo foi dividido nas seguintes seções: A Situação Alemã No Imediato Pós-Guerra; Os Legados da República de Weimar e do Regime Nazista; A Ocupação Aliada; "Melhores Pessoas Através De Construções Melhores"; o Modelo Alemão De Desenvolvimento; e Conclusão.

A Situação Alemã No Imediato Pós-Guerra
A II Guerra Mundial trouxe grandes danos para todo o mundo, em especial para o continente europeu, um de seus principais palcos. A ferocidade do exército alemão durante a sua campanha fez com que a retaliação por parte das forças aliadas fosse em uma mesma escala. A utilização de novas tecnologias e novas táticas de guerra, em especial do bombardeio aéreo causou tamanha destruição que até os dias atuais é possível ver os efeitos da guerra nas cidades.

Após o final da campanha aliada, a Alemanha se encontrar em ruínas, com seu parque industrial completamente tomado, ocupada pelos poderes aliados e sem nenhuma autonomia.Apesar de não ser uma ideia nova, o bombardeio aéreo começou a ser utilizado em larga escala durante a II Guerra Mundial. Segundo os dados do United States Strategic Bombig Survey, mais de 500.000 toneladas de bomba foram jogadas em território nazista durante 19431945, visando não só destruir parques industriais, mas também com o intuito de destruir cidades e assolar o espírito da população alemã, enfraquecendo a causa nazista. Um exemplo dessa estratégia foi o bombardeio de Dresda 1945, que tinha como propósito, além de matar pessoas, a destruição de símbolos da cultura alemã. O impacto dos bombardeios aliados foi devastador. Somente na cidade de Hamburgo, é estimado que 35.000 civis foram mortos e 125.000 feridos. Aproximadamente $80 \%$ das habitações foram danificadas e 50\% destruídas, além de 15 igrejas e 54 monumentos históricos (DIEFENDORF, 1993).

Apesar de não serem claras as estatísticas do período, estima-se que morreram,em toda a Alemanha, entre 400.000 e 600.000 civis, além de um número ainda maior de feridos, podendo totalizar 850.000 civis. A infraestrutura das cidades também sofreu grandes danos. É estimado que cerca de $50 \%$ das construções das cidades com mais de 100.000 habitantes foi destruída ou danificada(DIEFENDORF, 1993).

A campanha de bombardeio aéreo tinha o intuito de destruir os parques industriais e o espirito alemão. Liddell 


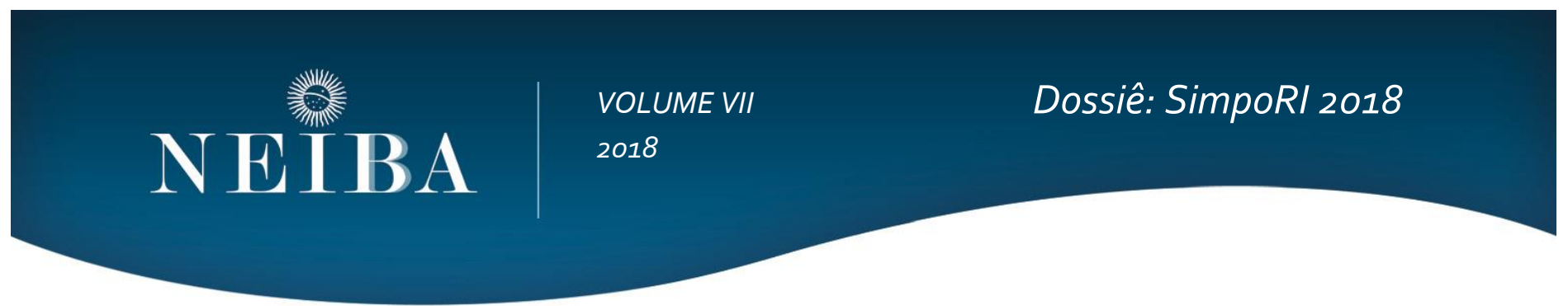

Hart, entre outros estrategistas militares, acreditava que os bombardeios destruiriam os centros nervoso de um estado e assolariam a moral dos nacionais que ali vivessem. No entanto, quando as tropas aliadas entraram em solo alemão, eles perceberam que não tinham conseguido nem destruir o parque industrial alemão e nem o espirito da população.

Após a rendição alemã, as cidades se encontravam em ruínas, com grandes pilhas de escombros. Mesmo abatidos com a derrota, os alemães enxergaram a destruição de suas cidades como uma chance de recomeçar e de recriar suas cidades

\section{"Pessoas Melhores Através De Construções} Melhores"

A arquitetura e cultura alemã foram extremamente marcados pelo período do regime Nazista. Durante o Terceiro Reich, Albert Speer, arquiteto pessoal de Hitler, buscou reunir um grupo de arquitetos e urbanistas para pensar na reconstrução das cidades alemães no pós-guerra. O padrão de cidade idealizado por Konstanty Gutschow era uma cidade estruturada e dispersa, de forma a ser mais resistente a bombardeios. O bombardeio de Hamburgo serviu para fortalecer ainda mais a ideia de Gutschow, que viu o bombardeio como uma "benção" para o futuro urbanismo previsto por Speer e Hitler (LEICK et al, 2010)

A destruição alemã é tão grande que ainda hoje é possível ser vista nas cidades. Após o final da guerra, os destroços resultantes dos bombardeios foram acumulados em grandes montes chamados de Schuttberg. Esses montes estão espalhados por diversas cidades da Alemanha, alguns chegando a mais de 50 metros de altura. Somente em Berlim, existem pelo menos 8 Schuttbergs, sendo o mais famoso deles o Teufelsberg (A Montanha do Diabo), com 55 metros de altura e 75 milhões de metros cúbicos de destroços. Teufelsberg é o ponto mais alto de Berlim Ocidental, o que fez com que os EUA construíssem uma estação de rádio, de forma a captar transmissões feitas do lado comunista.

Com o fim do regime nazista e a consequente perseguição aos seus seguidores, os projetos de Speer e Gutschow foram logo deixados de lado. Os arquitetos que faziam parte do grupo de Speer se voltaram para o modernismo de Bauhaus ${ }^{1}$ como uma forma de se proteger e evitar perseguições, adotando modelos desenvolvidos na década de 1930. Os anos que se seguiram foram de grande importância para a construção civil e a recuperação econômica alemã.

Nos anos seguintes, a Alemanha começou um processo de reconstrução liderado pelos arquitetos que faziam parte do grupo de Speer, sem que esses estivessem presos aos ideais urbanísticos nazistas, mas mesmo assim, modernizando as cidades com largas vias para os automóveis e sendo melhor projetada de forma a acompanhar o crescimento da cidade de forma ordenada. Esses arquitetos acreditavam que poderiam fazer as pessoas melhores através de construções melhores", sendo assim um grande boom na construção civil possibilitou a reconstrução de escolas, hospitais, vias públicas, prédios oficiais e em especial residências, todas essas seguindo o padrão do modernismo estabelecido por Bauhaus. A simples ideia de construir algo que remetesse ao período nazista era logo repudiado, visto como uma apologia a um regime que deveria ser ostracizado da história alemã.

O resultado desse esforço foi a criação de cidades muito semelhantes espalhadas por toda a Alemanha, o que acabou por demonstrar um equívoco dos arquitetos alemães. A arquitetura não deve ser somente funcional, ela deve ser utilizada para ajudar a contar a história de um povo, os períodos de glória, assim como os sombrios. Sendo assim, uma nova onda de reconstrução recomeçou na Alemanha,

${ }^{1}$ Escola de artes estabelecida em 1919, que se tornou referência em Design e Arquitetura, sendo uma das maiores expressões do modernismo. 


\section{NEIBA}

buscando reconstruir fac-símiles das construções históricas que foram destruídas durante a guerra.

\section{Essas diversas ondas de reconstrução} impulsionaram a construção civil e a economia durante as décadas seguintes. Nos quinze anos seguintes ao final da Guerra, mais de 5,3 milhões de novos apartamentos foram criados, somente na Alemanha Ocidental. Durante a década de 1960, eram construídos em média 570.000 novos apartamentos por ano, culminando na quantia impressionante de 714.000 no ano de 1973 (LEICK et al, 2010). Após 1973, esse ímpeto começou a se reduzir, chegando a uma média de 100.000 novos apartamentos construídos por ano, no entanto esse boom foi um dos motivos para a recuperação econômica alemã.

\section{A Ocupação Aliada}

O período logo após o final da II Guerra Mundial foi decisivo para as décadas futuras da Alemanha. As forças aliadas não cometeriam o mesmo erro que cometeram em 1919, quando puniram pesadamente os derrotados da guerra e deixaram que estes se reconstruíssem sozinhos aos poucos. Dessa vez, os poderes aliados, em especial os EUA e a URSS, iriam observar de perto a reconstrução germânica.

A proposta americana para a reconstrução alemã passa pelo que foi chamado de os 4Ds": descartelização; desmilitarização; desnazificação; e democratização.Os objetivos dessa campanha eram: eliminar os carteis industriais, assim como colocar um fim na capacidade econômica de a Alemanha financiar uma nova guerra, ao mesmo tempo em que buscava perseguir os simpatizantes do regime nazista e instaurar um regime democrático para o Estado alemão. Dessa forma, o exército americano tinha o intuito de evitar a possibilidade da Alemanha conseguir levantar os recursos necessários para uma nova guerra (WILLOUGHBY, 2001).
Aliado a essa proposta, vinha o projeto de punição da Alemanha devido aos prejuízos causados pela guerra. $O$ primeiro passo seria a instauração de um governo Aliado que dividiria a Alemanha em 4 regiões de atuação, sendo cada uma das potências aliadas responsável por uma área. O futuro da Alemanha começou a ser traçado em ainda em 1945 durante as reuniões de Yalta, Potsdam e Teerã, aonde os três líderes das potências aliadas vencedoras, Stalin, Churchill e Truman discutiram as medidas necessárias para serem tomadas no pós-guerra. Em Washington, existia uma vontade de punir os alemães pela guerra, e o resultado dessas reuniões era a de que a Alemanha deveria permanecer como um país unido, mas governado pelas potências aliadas.

Durante as conferências, ficou definido que a Alemanha deveria realizar pagamentos de reparação para os países que sofreram com o regime nazista, além de que as potências deveriam desmantelar os equipamentos e fábricas que pudessem ser revertidas como esforços de guerra. Parte das vendas e o excedente desse capital em maquinas e equipamentos seria utilizado como pagamento das reparações de guerra, e amparado pelo Acordo de Potsdam, a URSS poderia se valer do trabalho forçado dos prisioneiros de guerra como parte dos pagamentos também (WILLOUGHBY, 2001).

Outra importante medida na época foi a decisão de acabar com as forças armadas alemães e manter constante vigilância sobre a economia alemã. Amaury Porto de Oliveira destaca a importância da propaganda antimilitarista, demonstrando "que a derrota não fora apenas militar, mas também moral" (OLIVEIRA, 2000 p. 18). A massacrada população alemã aceitou prontamente esse tipo de mensagem, uma vez que existia grande repúdio pelo exército alemão e o fracasso do nazismo em reunir os povos germanófilos. O regime nazista consegui criar divisões internas na Alemanha, assim como com os seus vizinhos, que se ressentiam das atrocidades causadas pela guerra. Sendo assim, a propaganda maciça americana, assim como a ideia 


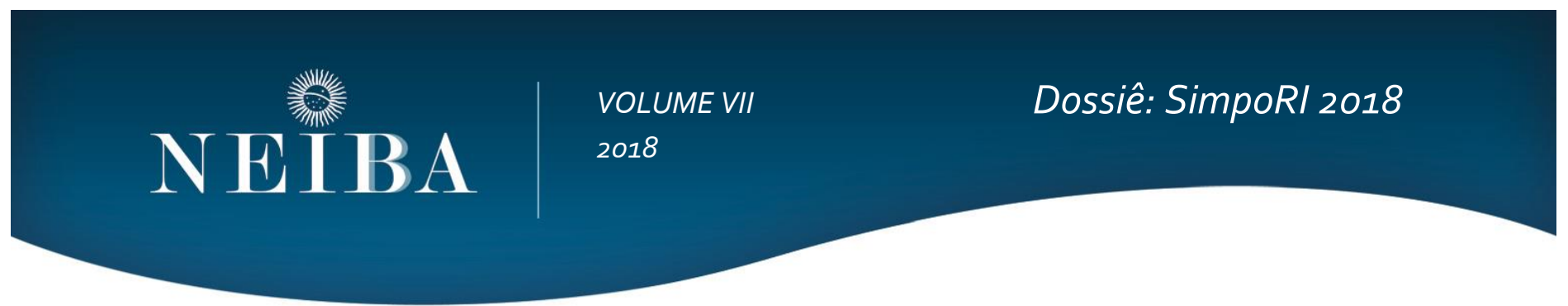

da democracia, ressaltado pela presença de suas forças armadas, que tinham a instrução de atuar como exemplos vivos da democracia, foram bem recebidos pelo povo alemão.

As mudanças no cenário internacional provocados pelo início da guerra fria fez com que a Alemanha tivesse uma autonomia um pouco maior. O Chanceler Konrad Adenaver compreendia que somente com o apoio e a coordenação de ações com os aliados, seria possível ter alguma autonomia. Um passo importante para o reestabelecimento da autonomia alemã foi a criação da Lei Básica da República Federal da Alemanha em 1948.

Diferentemente do caso japonês, a Lei Básica República Federal da Alemanhafoi criada por um parlamento alemão formado em Bonn com esse propósito em 1948/49. O fato da Lei Básica ter sido criado por um poder alemão e não imposta por aliados, demonstra a vontade dos aliados em dar maiores poderes e liberdades para a Alemanha, mesmo que continue sob vigilância continua.

Mesmo com uma maior autonomia, os EUA ainda se recusavam a emprestar dinheiro para pagar as reparações de guerra. O grande aporte financeiro voltado para Europa no pós-guerra foi o Plano de Recuperação Europeia, também conhecido como Plano Marshall, foi anunciado em 1948 pelo presidente norte americano Harry Truman e ia de encontro com as ideias de Jean Monnet, estadista francês, que visava criar uma maior integração no continente europeu, além de ser visto como uma forma de equacionar as rivalidades entre França e Alemanha. Visando uma maior integração do continente europeu, o governo americano demandou que os recursos provenientes do Plano Marshall fossem distribuídos em comum acordo entre os países europeus, forçando-os a cooperar e coordenar para a suas recuperações econômicas. O resultado dessa cooperação foi a criação da Organização para a Cooperação Econômica (OECE), que veio a se tornar a OCDE, cuja função, a princípio, era administrar e distribuir os recursos do Plano Marshall.
Richard Aldrich (1997) buscou demonstrar que os formuladores de política norte americanos entendiam que a unificação europeia era importante não só por si própria, mas também como um meio de resolver a questão alemã, permitindo que os EUA pudessem atuar em outros tabuleiros estratégicos. Outro importante ponto desse período foi a lógica que guiava a grande estratégia norte americana e sua política externa, a Lógica da Porta Aberta, que se baseava na premissa de que a prosperidade e manutenção do poder norte americano estava conectado com a recuperação econômica europeia (LAYNE, 2006). Para atingir tal objetivo, era necessário substituir as antigas rivalidades europeias e mercados nacionais por uma aliança e um mercado único. Essa política também tinha um lado mais pragmático. Ao fortalecer as economias europeias e promovendo estabilidade nos países centrais, seria mais difícil dos partidos comunistas ascenderem ao poder e ameaçar os objetivos norte-americanos.

Os EUA entendiam a recuperação a Alemanha como vital para a recuperação europeia, e contava com o Reino Unido para liderar o projeto. No entanto, o Reino Unido não tinha interesses e nem estabilidade econômica para liderar o projeto e sendo assim não buscaria nada mais do que a cooperação intergovernamental, a fim de auxiliar na recuperação europeia. Os líderes franceses tinham como objetivo principal reduzir a ameaça alemã, reduzindo a diferença entre o poderio econômico alemão e o francês, e diminuir a independência da Alemanha (LAYNE, 2006). Eles acreditavam que somente mantendo Alemanha sob constante supervisão e controle, a França, a Europa e consequentemente o mundo, poderiam ter segurança mais uma vez.

A lógica por trás da estratégia francesa era bastante diferente da estabelecida pelos políticos norte-americanos, que compreenderam a recuperação da Alemanha como fundamental. A estratégia francesa era bifacetada, visando o fortalecimento econômico francês e, ao mesmo tempo, o enfraquecimento da Alemanha. 


\section{NEIBA}

Para atingir tal objetivo, o governo francês elaborou um plano, o Plano Monnet, que visava reconstruir as empresas e o fortalecimento da economia francesa, transformando a França no centro do sistema europeu. Ao atingir esse plano, a França ultrapassaria a Alemanha como a maior produtora de aço do continente e ao mesmo tempo iria quebrar as empresas alemãs. A divergência entre os planos francês e americano fez com que os formuladores de política norte-americanos buscassem influenciar os políticos franceses, cooptando por uma abordagem mais europeia e menos nacionalista. O plano Marshall foi fundamental para atingir tal objetivo (LAYNE, 2006)

O anúncio do plano de recuperação europeu, o Plano Marshall, não foi visto com bons olhos pelos Soviéticos, que preferiram não participar da ajuda econômica para a recuperação da Europa. A renúncia soviética em participar do plano possibilitou George Marshall se utilizar do argumento de que seu plano era parte da estratégia de contenção da expansão da ameaça soviética na Europa, fazendo com que esse fosse visto com bons olhos pelos parlamentares e lobistas em Washington.

O Plano Marshall não foi a primeira ajuda financeira que os EUA cederam aos países europeus. Antes de seu lançamento, os EUA já tinham aportado mais de 600 milhões de dólares para a recuperação francesa. O pacote de ajuda foi anunciado as vésperas da eleição nacional francesa, visando influenciar o resultado dessa para os partidos anticomunistas e de centro. O Plano Marshall demonstrou uma mudança na relação entre EUA e Alemanha. Essa mudança acabou por alterar também a percepção americana da cooperação com os administradores soviéticos.

Devido ao fato de a URSS não participar do Plano Marshall e a Alemanha ser uma das favorecidas, veio a compreensão de que a Alemanha deveria ser dividida e que a sua parte ocidental deveria se integrar com o restante da Europa Ocidental. Sendo assim, a criação da República Federal da Alemanha se tornou parte do plano americano, possibilitando o desenvolvimento de um novo estado alemão sem a influência direta da URSS.

\section{Os Legados da República de Weimar e do Regime} Nazista

A arquitetura e a construção civil não foram os únicos legados provenientes dos períodos da República de Weimar e do regime nazista. Assim como a destruição causada pela guerra não pode ser dada como a única explicação para a impressionante recuperação econômica alemã no pós-guerra. Sendo assim, é importante pensar em o que possibilitou o crescimento da Alemanha na década de 1950? Ou ainda melhor, quais os motivos que a Alemanha não demonstrou a mesma recuperação em 1920?

Após o final da I Guerra Mundial, a Alemanha sofreu duras penas com o Tratado de Versalhes, o que fez com que esta tivesse grandes dificuldades em se recuperar economicamente. No entanto, se no início da década de 1920 a situação germânica estava ruim, após a Grande Depressão ela só veio a piorar. Com a Crise de 1929, os fluxos econômicos entre os EUA e a Alemanha cessaram complicando ainda mais a recuperação germânica. No entanto não foi somente a Crise de 1929 que foi o diferencial entre esses dois períodos, a estrutura alemã também tinha mudado com os períodos da República de Weimar e do Regime Nazista.

Karl-Heinz Paqué (2010) busca explicar os motivos para o crescimento econômico alemão na década de 1950 contrapondo com a ideia de Mancur Olson. Segundo Olson, a República de Weimar acabou por possuir grandes fraquezas institucionais permitindo que os grupos de interesse pudessem ter grande influência nos rumos da economia alemã de forma a perseguir objetivos particulares. No entanto, o crescimento da economia alemã no pós-guerra pode ser explicado por três fatores-chave: $O$ nazismo e a guerra causaram tanta destruição física e social, que acabou por permitir que o crescimento no pós guerra não fosse 


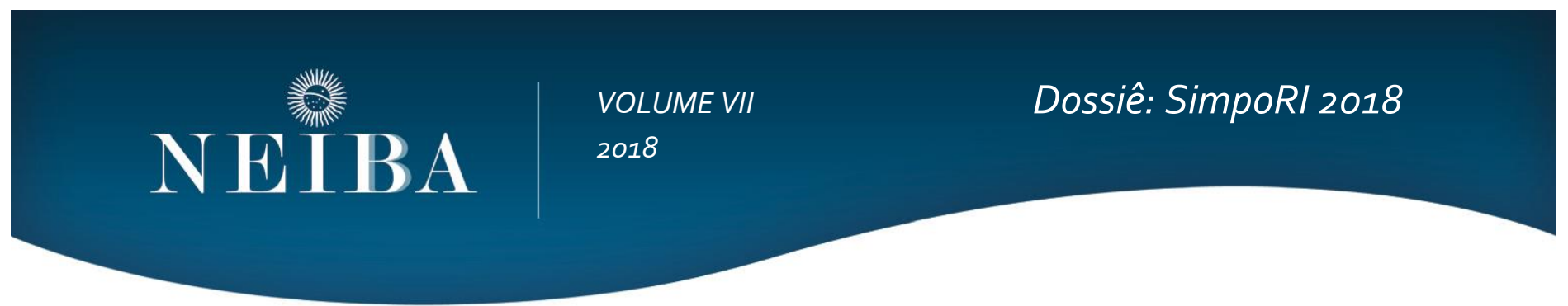

atrapalhado pela burocracia ou pela esclerose institucional; o ressurgimento das coalizões permitiu uma melhor prevenção da divergência de interesses; com o tempo, a economia voltou a sofrer os impedimentos, o que explicaria o final do milagre alemão durante a década de 1960 .

Paqué debate que a República de Bonn - surgida após o estabelecimento da Lei Básica - é uma continuação da República de Weimar, após as interrupções do regime nazista e o governo dos aliados. Tanto o regime nazista como o governo dos aliados deixou marcas profundas na sociedade alemã que acabaram por impulsionar a Alemanha, mas a grande influência da República de Bonn foi a transformação para uma democracia que ocorreu no final da I Guerra Mundial.

Outro importante fator foi o ressurgimento de três tipos de organização social: sindicatos, partidos políticos e associações de negócios. Esses três tipos de organizações ressurgiram logo após o final da II Guerra Mundial e, assim como aconteceu na arquitetura, trouxeram ideais anteriores ao período do regime nazista, se voltando para os ideias de Weimar. O rápido ressurgimento desses três grupos acabou por acelerar o crescimento econômico permitindo uma recuperação econômica mais rápida do que no período entre guerras.

A interpretação de Paqué sobre o grande crescimento da economia germânica em 1950 é baseada em dois pontos: que a barganha coletiva formaria uma cartelização dos grupos de interesse e de negócios e a manutenção da força de trabalho; e os condicionantes externos.

Paqué buscou demonstrar que a barganha coletiva e a formação de carteis acaba por formar grupos de interesses mais fortes e maiores, o que acabaria por influenciar de forma mais decisória as medidas do país. Essa questão aliada ao grande desemprego gerado no período pós-guerra fez com que grande parte da economia internacional alemã fosse voltada para o exterior e para as exportações.

No entanto somente esses dois fatores não seriam o suficiente para que o milagre alemão ocorresse. A situação internacional, tanto da formação de um mercado europeu, como participação direta dos EUA em sua recuperação econômica fez com que a economia alemã desse um salto sem precedente durante quase 15 anos seguidos.

René Dreifuss (2000) ressalta a importância da Alemanha em possuir uma política externa voltada para o ocidente, apoiada pelos EUA, Reino Unido e França, e uma voltada para o oriente, apoiada pela URSS. Essa situação única de se encontrar no epicentro do conflito da Guerra Fria, aliada a sua condição desmilitarizada, permitiu que a Alemanha focasse em um âmbito mais regional, visando a recuperação da Europa e o seu próprio fortalecimento econômico e político.

Os dois fatores levantados por Paqué acabam por estar mais alinhados com o que Gilpin acabou por definir como o modelo alemão de política econômicas.

\section{O Modelo Alemão De PolíticaEconomia}

Robert Gilpin em seu livro seminal Global Political Economy busca analisar três modelos de política econômica, o americano, o japonês e o alemão, demonstrando as similaridades e diferenças de cada um deles. Em cada modelo, o autor busca analisar o papel do Estado na economia, a estrutura do setor empresarial e as práticas corporativas e os mecanismos de governança corporativa e práticas das empresas privadas. No caso alemão e japonês, Gilpin ressalta ainda o papel dos bancos e de outros stakeholders.

O modelo alemão de política econômica possui ênfase nas exportações, poupança e investimento, mais que consumo, principalmente devido ao fato de que grande parte da população não se encontrava em condições de consumir 


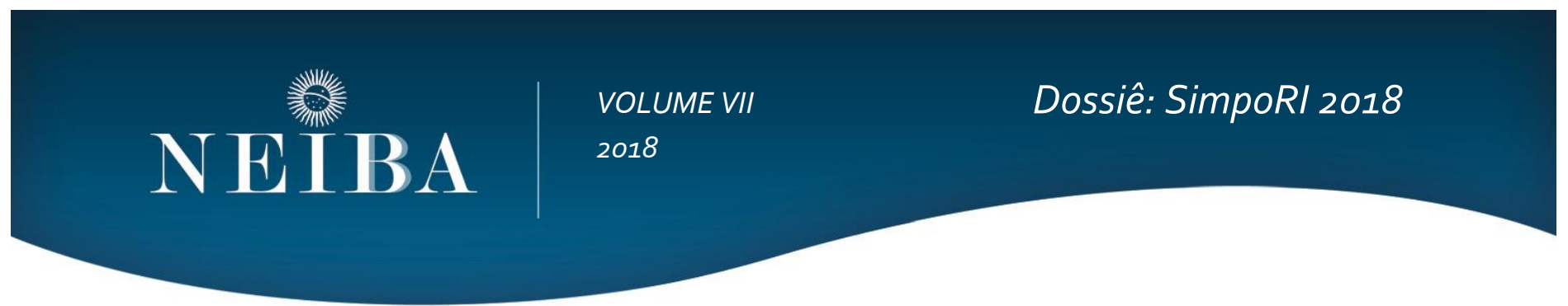

muito da produção industrial alemã, uma vez que muitos tinham perdido tudo ou quase tudo durante a guerra. $O$ Estado alemão, por sua vez, faz o papel de provedor de um ambiente de negócios estável, através de um conjunto de leis altamente desenvolvido, provendo também uma maior previsibilidade, gerando um clima mais favorável para os investimentos.

Gilpin define o modelo alemão como "capitalismo de bem-estar social", que seria um resultado da cooperação entre capital, sindicatos e governo, gerando uma sociedade com altíssimo custo, cerca de $80 \%$ do salário, o que por sua vez força a ser uma economia com alta produtividade. Alguns exemplos desse "capitalismo de bem-estar social" é a Lei da Co-gestão, que determina que os conselhos empresariais tenham o mesmo número de empregados e gerentes nas diretorias.

O sistema de formação de cartéis, alianças entre as empresas e seus laços estreitos com os bancos, permitiu também um alto desenvolvimento do ambiente de negócios, além de uma cumplicidade, alinhamento de interesses e parcerias que fizeram com que a economia alemã se tornasse um grande exemplo até os dias de hoje

\section{Conclusão}

O período do imediato pós-guerra foi um período de grandes transformações não só para a Europa, mas também para todo o mundo. No meio desse turbilhão de transformações, alguns estados se destacaram através de seu desenvolvimento econômico e participação na política regional e mundial. Esse foi o caso da Alemanha.
Após o final da guerra a Alemanha se encontrava destruída, dividida e ocupada, buscando cortar de vez quaisquer traços do regime nazista, com grande parte de suas cidades em ruínas ou extremamente danificadas e com uma economia fraca. Aliado a esse cenário, a Alemanha ainda era vista como um estado a ser controlado, mantido sob rédeas curtas, visando evitar qualquer chance de um ressurgimento que pudesse possibilitar uma nova ameaça.

No entanto, mesmo com condições não ideias, a Alemanha conseguiu se desenvolver economicamente e foi capaz de dar um grande salto econômico se tornando novamente uma das maiores economias mundiais e centro da economia europeia. Esse "milagre" alemão só foi possível graças a uma combinação de fatores que forjaram a Alemanha como ela é hoje.

Tanto a explicação de Mancur Olsen como a de KarlHeinz Paqué servem para explicar o período de alto crescimento alemão na década de 1950. Apenas através de uma combinação entre essas duas explicações, buscando compreender as diversas facetas da sociedade alemã, aliado aos condicionantes externos, como o papel dos EUA e da Guerra Fria, e a necessidade de reconstrução dado nível de destruição das cidades é capaz de explicar o rápido crescimento alemão no período pós-guerra.

Por fim, o caso alemão é um excelente estudo de caso de como a história e as mudanças internas e externas acabam por formar a economia política de um país, formando um modelo totalmente novo que possuí traços de diversos períodos e sistemas, como a República de Weimar, o regime nazista e o governo das potências aliadas.

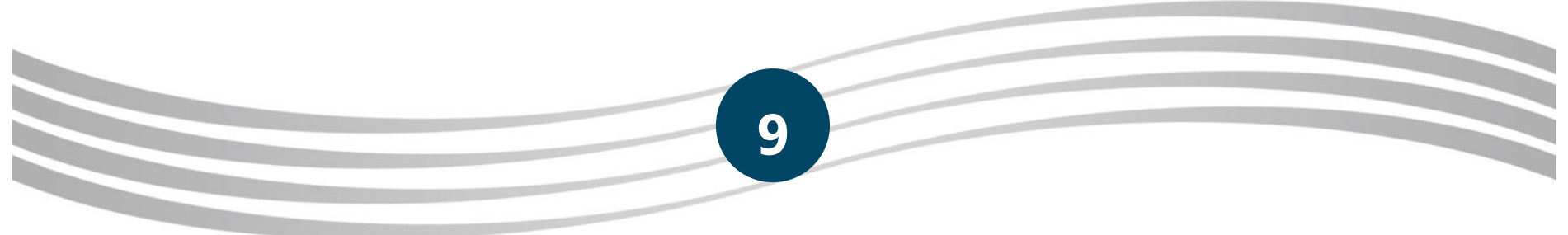




\section{NEIB}

VOLUME VII

Dossiê: SimpoRI 2018

2018

\section{BIBLIOGRAFIA}

ALDRICH, Richard J. CIA and European unity: The American committee on United Europe.

http://www2.warwick.ac.uk/fac/soc/pais/people/aldrich/publications/oss_cia_united_europe_eec_eu.pdf

CARVALHO, Patricia et al(2013). The influence of the United States in the processes of regional integration in Europe, Latin America and Southeast Asia ISA Annual Convetion, San Francisco.

CRAFTS, Nicholas; TONIOLO, Gianni(2010). Economic Growth in Europe since 1945 Cambridge University Press, Cambridge.

DIEFENDORF, Jeffry(1993). In the Wake of War: the reconstruction of German cities after World War II. OUP, Nova York.

DINAN, Desmond(2007). The European Integration Process In: HAY, Colin; MENON, Anand. European Politics (eds.)(2007). Nova York: Oxford University Press.

DREIFUSS, René(2000). A Visão Estratégica na Construção do Futuro da Alemanha. In: PINHEIRO GUIMARÃES, Samuel (org)(2000). Alemanha: visões brasileiras. FUNAG, Brasilia, 2000.

GILPIN, Robert (2001). Global Political Economy. Princeton: Princeton University Press.

HAY, Colin; MENON, Anand(2007). European Politics. Nova York: Oxford University Press.

LAYNE, Christopher(2006). The Peace of Illusions: American Grand Strategy from 1940 to the Present. New York, Cornell University Press.

LEICK, Romain et al(2010). Out of the Ashes: a new look at Germany's postwar reconstruction. Disponivel em:

$<$ http://www.spiegel.de/international/germany/out-of-the-ashes-a-new-look-at-germany-s-postwar-reconstruction-a-702856.html >Spiegel Online. Acessado em 25/08/2016.

OLIVEIRA, Amaury(2000). A Questão Alemã Desgasta a Pax Americana. In: PINHEIRO GUIMARÃES, Samuel (org)(2000). Alemanha: visõesbrasileiras. FUNAG, Brasilia.

PAQUÉ, Karl-Heinz(2010). Why the 1950s and not the 1920s? Olsonian and non-Olsonian interpretations of two decades of German economic history. In: CRAFTS, Nicholas; TONIOLO, Gianni(2010). Economic Growth in Europe since 1945 Cambridge University Press, Cambridge.

PINHEIRO GUIMARÃES, Samuel (org)(2000). Alemanha: visões brasileiras. FUNAG, Brasilia.

WILLOUGHBY,John(2001). Remaking The Conquering Heroes: the social and geopolitical impact of the Post-War American occupation of Germany. Nova York, Palgrave. 